\title{
Improving the allocation of flood-risk interventions from a spatial quality perspective
}

\author{
Anne Loes Nillesen \\ Faculty of Architecture, Department of Urbanism, Delft University of Technology, \\ and D.EFAC.TO Urban Design, The Netherlands
}

\section{Abstract}

This paper describes an integral approach to flood-risk protection and spatial design that allows for an active involvement of landscape architects and urban designers in the allocation of flood-risk interventions within the Dutch Delta. The Dutch Rijnmond-Drechtsteden area is used as a case study to demonstrate how choices regarding the scale and layer of a flood-risk intervention can shift the location of that intervention. A spatial assessment framework is used to test the spatial impact of different flood-risk interventions at different locations, and determine where the intervention is most required from a spatial point of view.

Dutch Delta / integral flood-risk design / research-by-design method / urban design principles

\section{Introduction}

Delta regions throughout the world are subject to increasing flood-risks. These regions often have high population numbers and make a significant contribution to GDP; approximately 50 percent of the world's urbanized areas are located in deltas (UN-Habitat 2006). Countries such as the Netherlands, Bangladesh, and Vietnam, and cities such as Jakarta and New York, are developing flood protection strategies to protect inhabitants and economic centres against flooding.

This paper concentrates on the Netherlands, where ongoing subsidence, climate change, the growing economic value of low-lying parts of the country, and the discovery of new failure mechanisms of dykes have created a significant long-term flood-risk challenge. In response to this, the Dutch government established the Delta Programme. The aim of this programme is to develop long-term strategies to provide protection against flooding. Its main focus is on developing high-level choices with respect to the scale and type of interventions that are required. At the same time, the programme needs to ensure that the Dutch Delta remains an attractive place in which to live, work, recreate, and invest (Deltacommissie 2008: 11). In order to develop sustainable urban deltas, there is a need for interdisciplinary approaches in which urban designers and civil engineers can collaborate (Meyer 2009: 385).

Several studies present typologies and design principles for integral design on a local scale to integrate dykes (Stokman et al. 2008; Veelen et al. 2010), revitalize river fronts (Prominski et al. 2012), obtain extra space for water (Baca Architects et al. 2009), and design flood-proof houses (Nillesen $\mathcal{E}$ Singelenberg 2011). The Delta Urbanism book series aims to deliver methods for urban design on the scale of the delta. The publications stress the need for interdisciplinary approaches (Meyer 2009: 97) and show interesting examples of regional design and scenario studies addressing floodrisk protection, but the contours of such approaches remain undefined. Both the Dutch Dialogues project and the Atelier for Coastal Quality have been successful in setting up workshop series in which designers and experts from other disciplines worked together (Atelier Kustkwaliteit et al. 

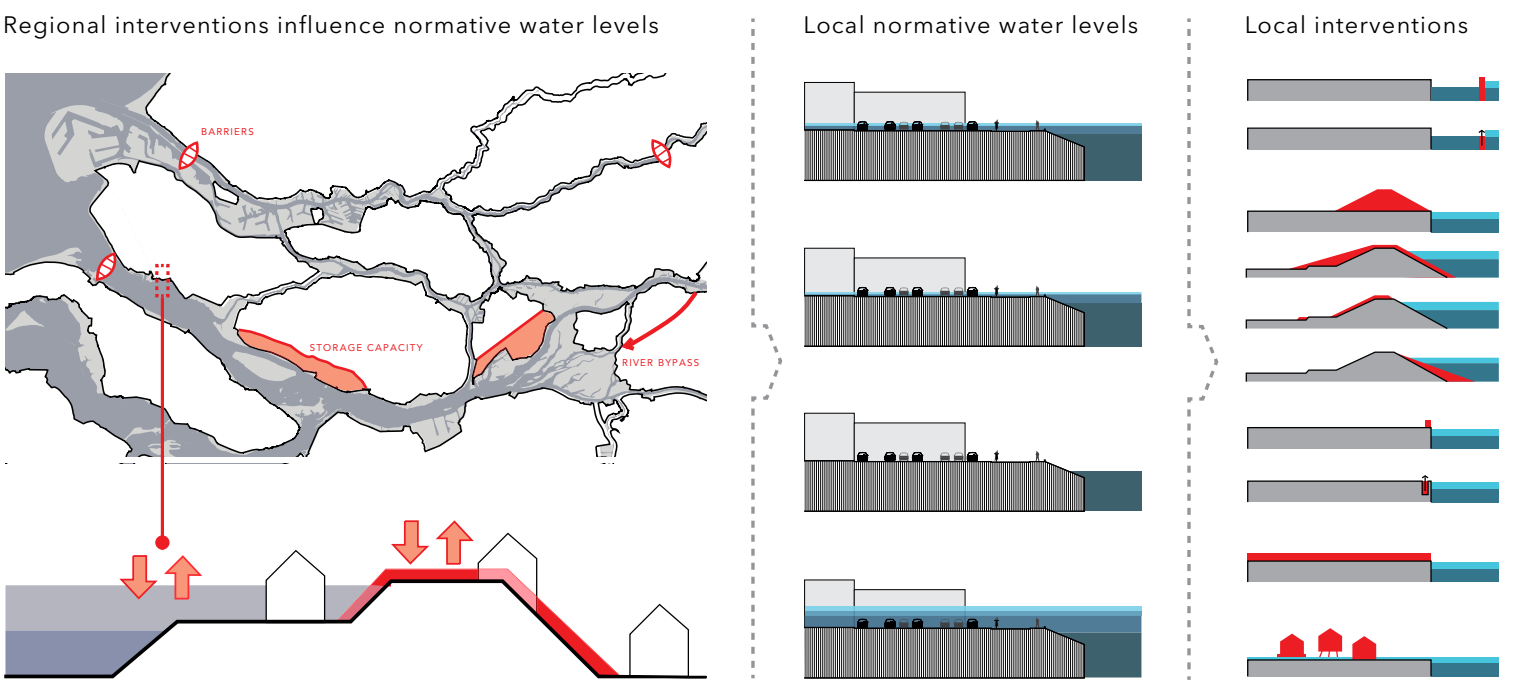

Figure 1 Schematic representation of the impact of regional flood-risk interventions on local flood-risk interventions. Regional interventions influence the local water levels and flood-risk assignments and, with that, the probable local flood-risk interventions.

2013; Meyer, Morris \& Waggonner 2009). The recent flood-protection project Room for the River introduces Quality Teams, consisting of experts in the field, established to ensure the enhancement of spatial quality in relation to flood-risk protection measures (Klijn et al. 2013).

The existing approaches to integrate flood-risk and spatial design either study the effects on or potentials of alternative interventions for the surroundings to formulate a preference, embed necessary flood-risk interventions in a qualitative way, or exploit the potential for synergy at locations where flood-risk and spatial assignments overlap. On a local scale, a flood-risk assignment is often approached by interdisciplinary teams of spatial designers and civil engineers; the assignment itself, however, remains a given fact and is defined in an earlier research stage by civil engineers. Landscape architects and urban designers only get involved in studies at a later stage (Prominski et al. 2012: 16), limiting their role to the task of optimally embedding a flood-risk intervention at a given location, in order to achieve the best possible spatial quality.

This paper presents the first contours of a method that combines the perspectives of flood-risk protection and spatial quality in an early analysis stage in which choices with respect to different scales and types of interventions within a delta are addressed. Flood-risk interventions can be implemented at different spatial scales and flood-risk layers, resulting in different locations of those interventions. As this paper demonstrates, this mechanism offers the potential to allocate interventions to locations in a delta that are most suitable from a spatial point of view, and thus enables a more prominent role for the spatial assignment of an area in the development of flood-risk strategies.

First, the method and its underlying concepts are explained. Then the main characteristics of the Rijnmond-Drechtsteden case study area in the Netherlands are described from a spatial and flood-risk point of view. Next the results from the application of the method in that case study area are described. The paper ends with conclusions and recommendations.
Methodology

In this section the underlying principles of the scale and layer of the flood-risk intervention are explained, as well as the research-by-design and spatial assessment method that are applied to shift the flood-risk intervention to a more favourable location.

\section{Research-by-design}

Research-by-design can be defined as: a study in which knowledge and understanding are generated by studying the effects of actively varying design solutions as well as their context (De Jong $\mathcal{E}$ van der Voordt 2005: 21 ). As will be demonstrated in the next sections, systematically applying flood-risk interventions on different scales and flood-risk layers will lead to different design solutions and interventions at different locations. In this study research-by-design is used to visualize and study the spatial impact of those varying design solutions and shifting contexts. This creates understanding about the spatial impact of high-level choices regarding the scale and layer of the flood-risk intervention. Once the impact is understood, the knowledge gathered can be used to select or create the most favourable flood-risk intervention strategy from a spatial point of view.

\section{The scale of a flood-risk intervention}

Flood-risk interventions can be implemented on different scales, varying from large (such as an entire delta system) and medium scales (such as polders and river branches) to local (such as a stretch of land or section of dyke within the delta) and small scales (such as a single building).

As shown in figure 1 , interventions on the scale of a delta system and the medium scale of river branches and dyke rings can influence water levels throughout the entire delta. As a result, the local flood-risk protection assignment can be changed and thus the need for specific local interventions. In order to demonstrate how this mechanism can be actively used to allow the shifting of local-scale interventions to the most suitable locations the following steps have to be taken: 


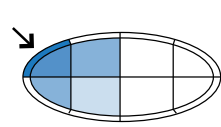

Breach location

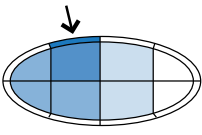

Breach location

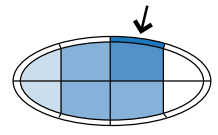

Breach location

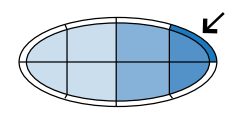

Breach location D

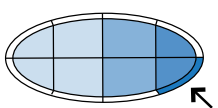

Breach location

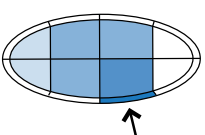

Breach location $\mathbf{F}$

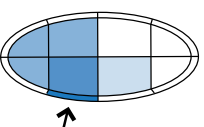

Breach location G

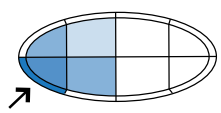

Breach location H

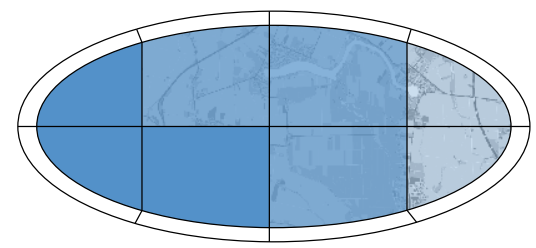

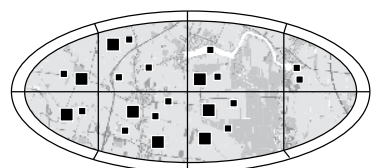

ECONOMIC DAMAGE in relation to the presence of economic value

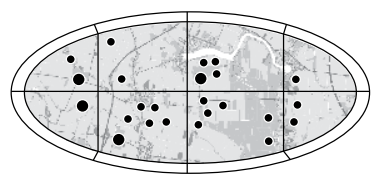

VICTIMS in relation to the presence of inhabitants
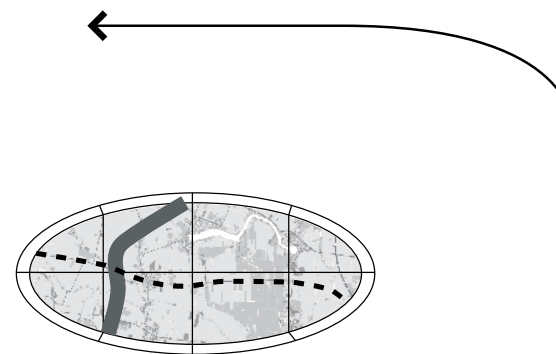

VITAL FUNCTIONS vital infrastructure and objects within the area

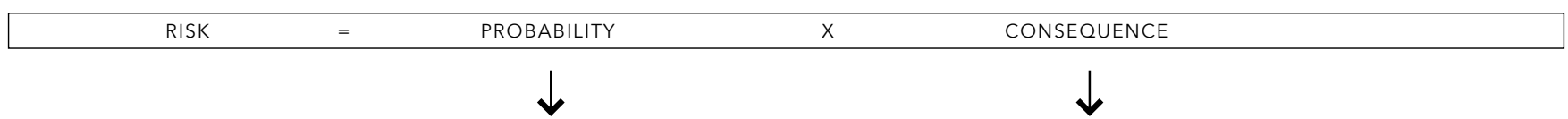

PATH 1: probability reduction

PATH 2: consequence reduction
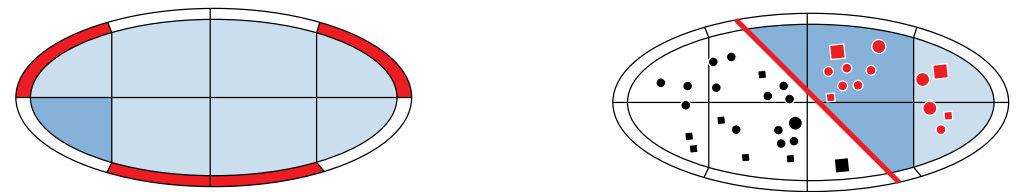

Figure 2 Schematic representation of the multi-layer safety approach showing the data as they were developed by the engineering company, as well as the proposed research-by-design method
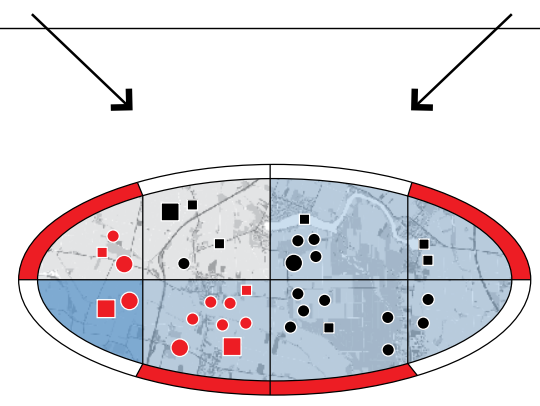

Potential interventions

- Identify the relevant flood-risk strategies on the medium and large scale that are effective from a hydraulic point of view.

- Visualize the impact on the local normative water levels.

- Let civil engineers describe appropriate flood-risk interventions at specific local sites, based on normative water levels.

- Let an expert team assess the impact of the flood-risk intervention on the spatial quality.
The layers of a flood-risk intervention

Flood risk is defined as the probability $\mathrm{x}$ consequences of a flood. Therefore interventions that reduce the probability of a flood are, at least to some degree, interchangeable with interventions that reduce detrimental consequences. Flood-risk interventions can be implemented on different'floodrisk layers'. A first one, the layer of the (1) probability, includes prevention measures such as dykes and barriers, and interventions that reduce the normative water level. Two others are related to consequences, namely (2) exposure, which includes interventions such as flood-proof buildings, the protection of vital infrastructures, compartmentalization, and restrictive building policies, and (3) vulnerability, which includes interventions that allow people to evacuate an area safely and allow a rapid recovery after a flood (Expertise Netwerk Waterveiligheit 2012). 


\begin{tabular}{|c|c|c|c|c|c|c|}
\hline EXPERT & $\stackrel{8}{\uplus}$ & $\frac{0}{5}$ & 5 & & & ฐ్ \\
\hline Functioning as residential, commercial, recreational, or public space & & & & + & - & 0 \\
\hline Accessibility and routing & & & & & & 0 \\
\hline Ecologic functioning & - & & & & & \\
\hline Maintainability & & + & + & & & + \\
\hline
\end{tabular}

\section{ATtRACTIVENESS}

Identity of the location / surroundings

Recognition of structures

Cultural recognition

Spatial recognition

Diversity/alteration

Uniqueness

Logic of spatial arrangement

Image

Water-safety experience

Attractiveness

Scale of intervention vs. local scale

Relation to the water

ROBUSTNESS

\begin{tabular}{l|c|c|c|c|c|}
\hline Reversibility & & & - & + & - \\
\hline Development potential & & + & - & + & 0 \\
\hline Multi-functional use of space & & & & + & - \\
\hline Robustness & & + & & + & + \\
\hline Flexibility & & & & + & \\
\hline Durability & & & & & \\
\hline
\end{tabular}

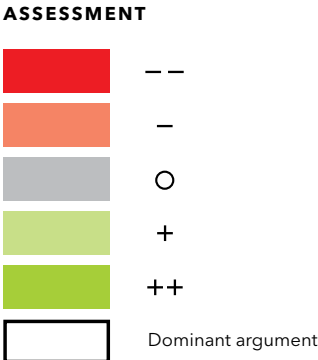

GROUP ASSESSMENT

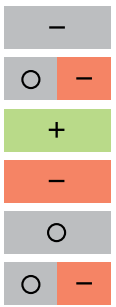

Figure 3 The spatial criteria list used in the expert session on spatial assessment
The proposed method is closely linked to the concept of flood-risk maps, such as used in the Dutch Delta Programme. A flood-risk map shows how deeply and within what time period areas will flood, and what the estimated number of fatalities and the economic damage suffered will be. As figure 2 visualizes, the map is an overlay of the consequences for several dyke breaks at different locations. This means that the flood risk in a random area within a dyke ring can either be targeted by local interventions that reduce potential damage, or by reducing the probability of a dyke break at a certain place that contributes to the flood risk at that location.

A differentiated design approach is proposed here in which flood-risk interventions on different layers work together. Specific locations that are preferred from a spatial point of view are used as a starting point for the flood-risk strategy. The design approach is cyclical: two parallel tracks for interventions that can reduce the probability or the consequences are investigated.

The following steps are taken to shift the flood-risk assignments to the most suitable locations:

1. Let an expert team select the flood-risk interventions that either

Have a positive effect on spatial quality and some effect on the flood-risk reduction. Have a neutral impact on the spatial quality and a considerable impact on the risk reduction.

2. Update the risk map so that the new or remaining focus points of the risk assignment are defined.

3. Address the remaining problematic risk areas with a second round of flood-risk interventions while using design optimization to embed the necessary interventions.

4. Update the risk map and, if necessary, repeat steps 3 and 4.
Spatial assessment framework

The spatial assessment framework used in this study builds on the 'Ruimtelijke Kwaliteits Toets' (spatial assessment framework) that was used by the Dutch Room for the River project (Bos, Lagendijk E Beusekom 2004). The assessment criteria are based on the definition of spatial quality as a combination of utility, attractiveness, and robustness. They are derived from previous studies on qualitative criteria (Hooimeijer, Kroon \& Luttik 2001; Gehl et al. 2006), and contain factors such as ecological functioning, maintainability, identity of the surroundings, recognition of structures, cultural recognition, alteration, logic of spatial arrangement, relation to the water, reversibility, development opportunities, and uniqueness.

In order to assess the impact of a flood-risk strategy, the following steps have to be taken:

- Adapt the spatial assessment framework to specific conditions for a case study area.

- Visualize the various (local-scale) locations that need to be evaluated in a consistent and neutral fashion.

- Assess the current situation as a reference, using an expert team and relevant criteria from the framework.

- Assess the new situation related to the flood-risk protection strategy, using an expert team and relevant criteria from the framework.

Figure 3 shows an example of the assessment list used in the RijnmondDrechtsteden area. Assessments can be judged positive, negative, or neutral. A positive assessment indicates that the flood-risk intervention may improve the spatial quality, or that synergy with the spatial assignment or ambition of the area is expected. A negative assessment indicates a negative impact on the existing spatial quality; it would be preferable to shift the necessary flood-risk intervention away from this specific location. 


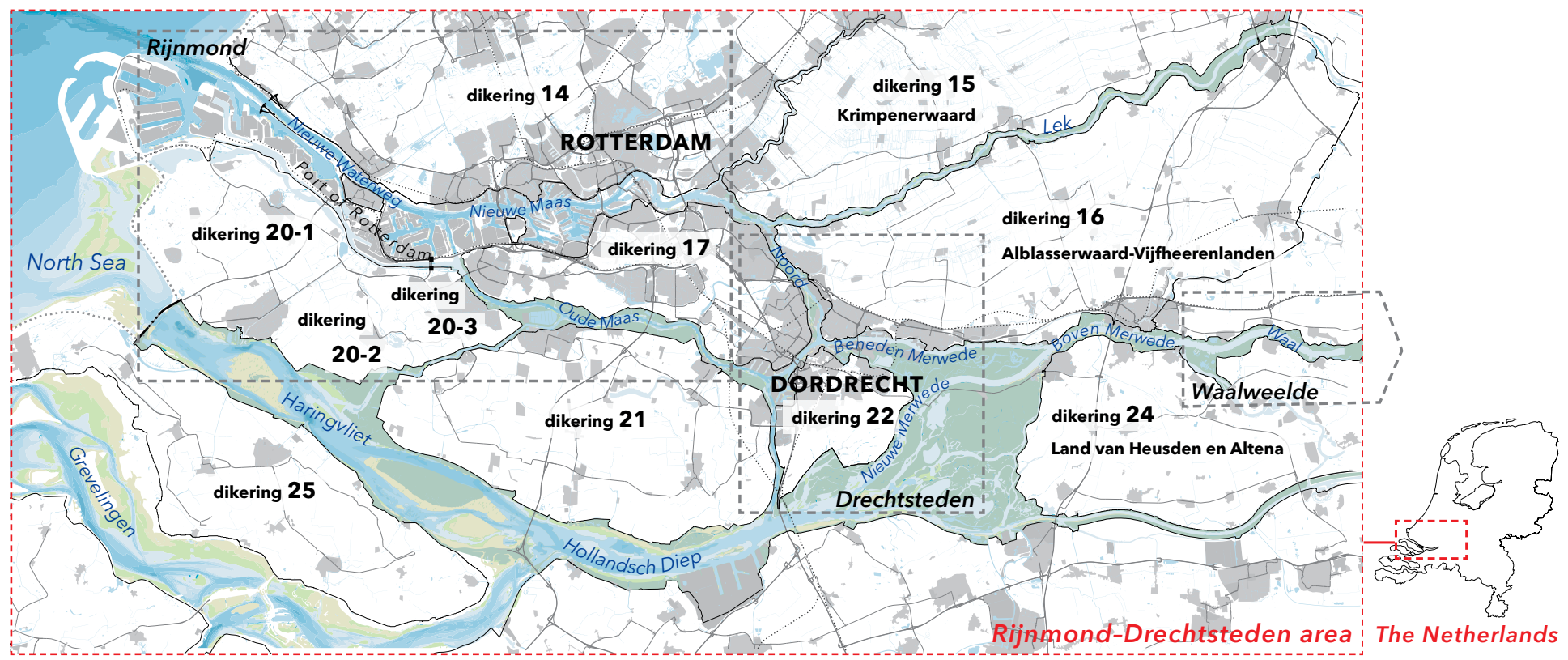

Figure 4 Map of the Rijnmond-Drechtsteden area

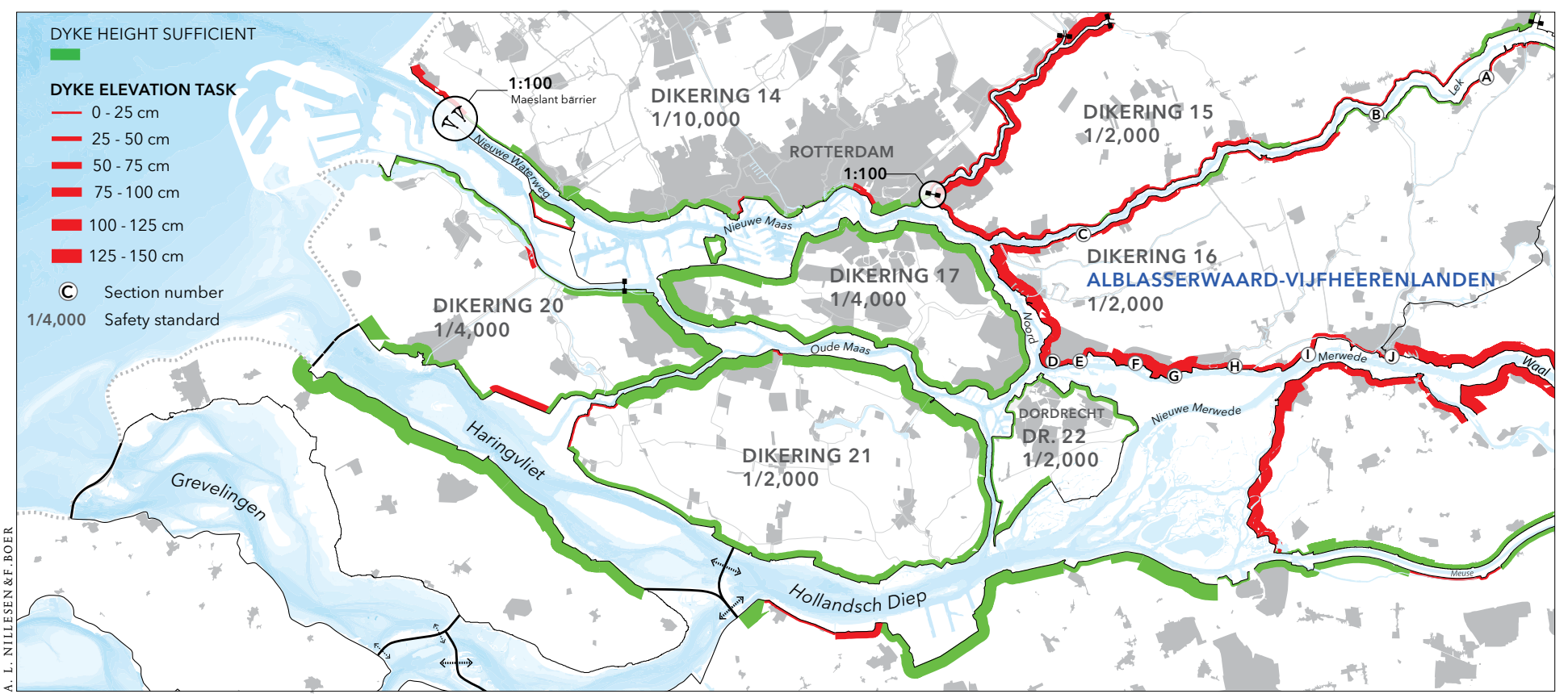

Figure 5 Indication of the regular dyke raisings planned according to the 'business-as-usual' flood-risk strategy for 2100, including land subsidence and climate change (Data: vd Kraan 2012) 


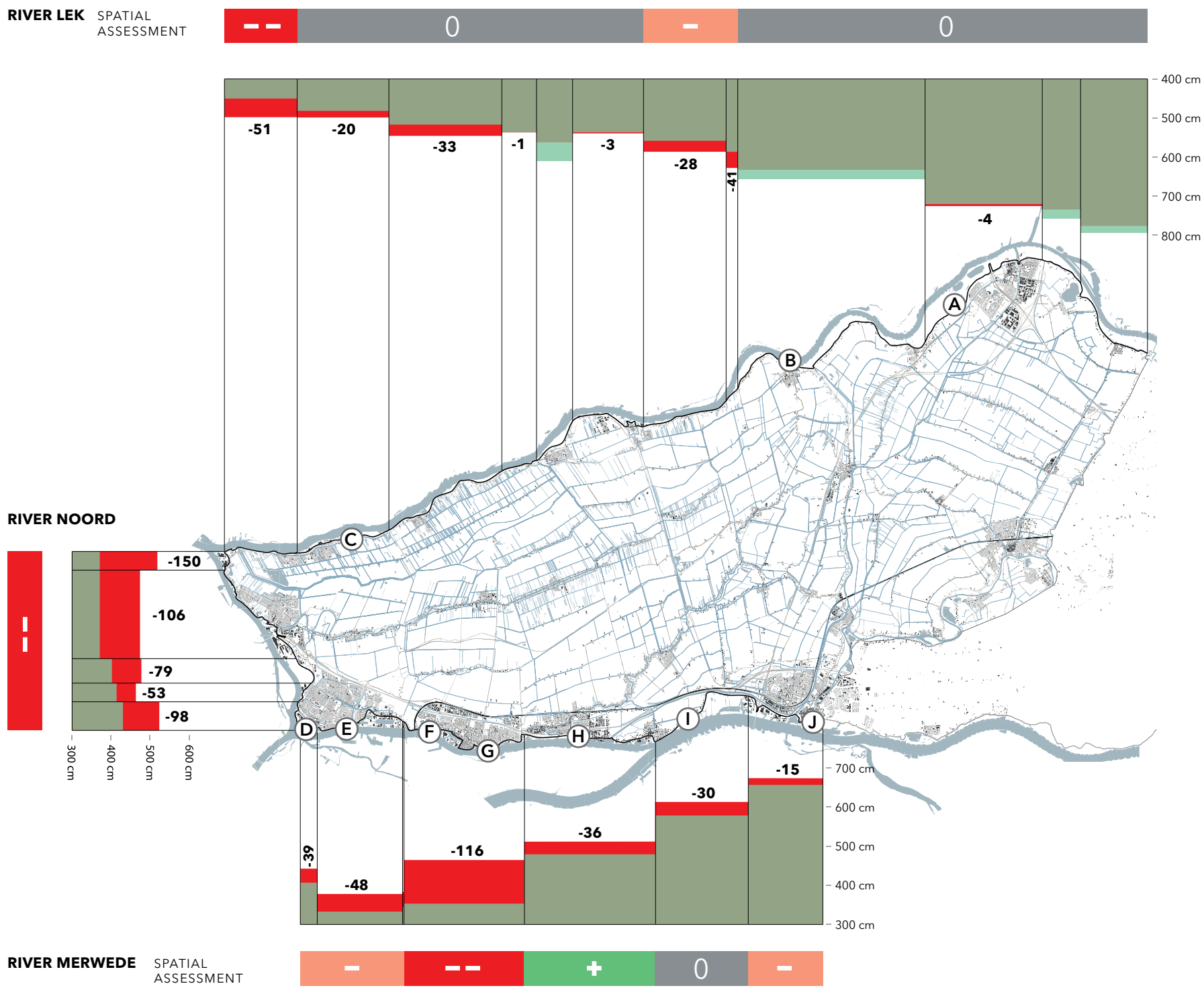

Figure 6 Map of the Alblasserwaard, including the dyke raising tasks for 2100 (Data: vd Kraan 2012)

The Rijnmond-Drechtsteden and Alblasserwaard areas

The Rijnmond-Drechtsteden area is shown in figure 4 and contains the greater Rotterdam area including the Port of Rotterdam, which is an important economic driver in this region. The area faces a twofold flood menace: it is threatened by storm surges at sea and, potentially simultaneous, peak river discharges. A system of dyke rings combined with a network of storm surge barriers protect the Netherlands against floods (Jonkman, Kok \& Vrijling 2008).

The Netherlands will have to extend its flood-risk protection system in order to maintain the current flood-risk standards with regard to the expected long-term flood-risk challenge. Currently the location and moment in time of flood-risk interventions are determined by the Dutch water boards, which are government bodies charged with a wide range of water-management responsibilities. They test the strength of dykes every six years and take action to heighten or strengthen them if current flood-risk standards are no longer met (Waterschap Hollandse Delta, website). Figure 5 , in red shows the dyke raisings that would be required for the year 2100 , also referred to as the 'business-as-usual' flood-risk protection strategy. We see an attention point around the subsiding peat polders of dyke rings 15 and 16. The Alblasserwaard (dyke ring 16) was selected as a case study area on the medium-scale level; the area and its dyke raising task are shown in more detail in figure 6. 

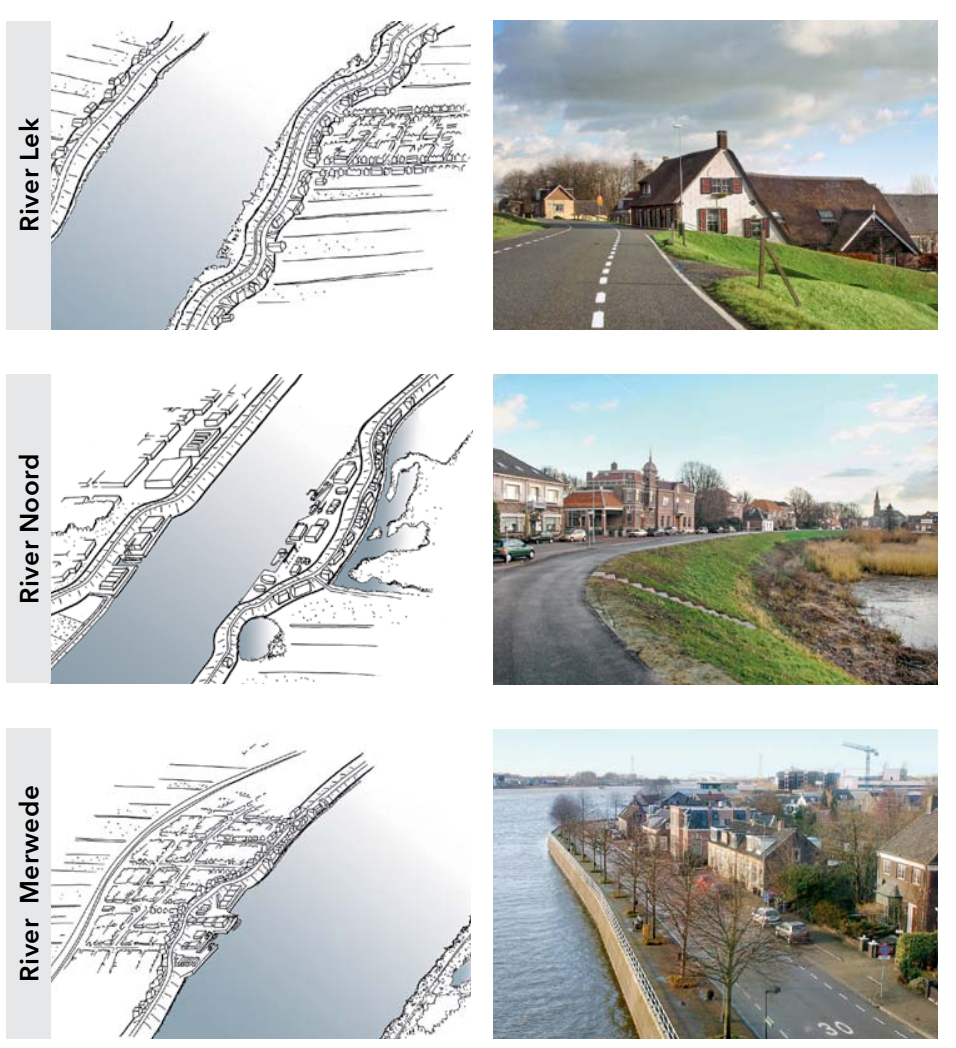

Figure 7 Sketch and pictures of the three rivers surrounding the Alblasserwaard

In the Alblasserwaard two main types of landscape can be distinguished: riverfronts and polders (Steenbergen et al. 2009: 251). The riverfronts are relatively densely built, while the open peatland polder mainly consists of grasslands, with the exception of some built-up ribbons along drainage canals. The polder has an extensive drainage system that includes the windmills of Kinderdijk, a world heritage site.

The pictures and sketches of the area in figure 7 show that the three rivers along Alblasserwaard have their own distinctive characteristics. The steep Lek dykes form a clear separation between the polder and the river. Along the Lek we find ribbons of individual houses and some villages inside the dyke ring. Dykes that were reinforced over time now almost absorb some of the dyke houses. The unembanked areas are used for extensive water-related industries, for recreation, or as floodplains. Along the Noord we find ribbons of small terraced houses, opposite a changing sequence of large industrial sheds, flood plains, and picturesque river views. The southern edge of the polder is most densely urbanized. The south-western edge of the Alblasserwaard polder is part of the Drechtsteden: an urban cluster positioned along the intersections of the rivers Merwede, Noord, and Oude Maas. The unembanked areas of this economic sub-centre have been raised and are mainly used for harbour-related activities, which obstruct the view of the river. Along both sides of the dyke are ribbons of terraced or detached houses positioned close to each other.

The expected shrinkage of the population after 2030 makes the liveability and identity of the area an important focus point in the regional vision of the Alblasserwaard area (Provincie Zuid-Holland 2012).
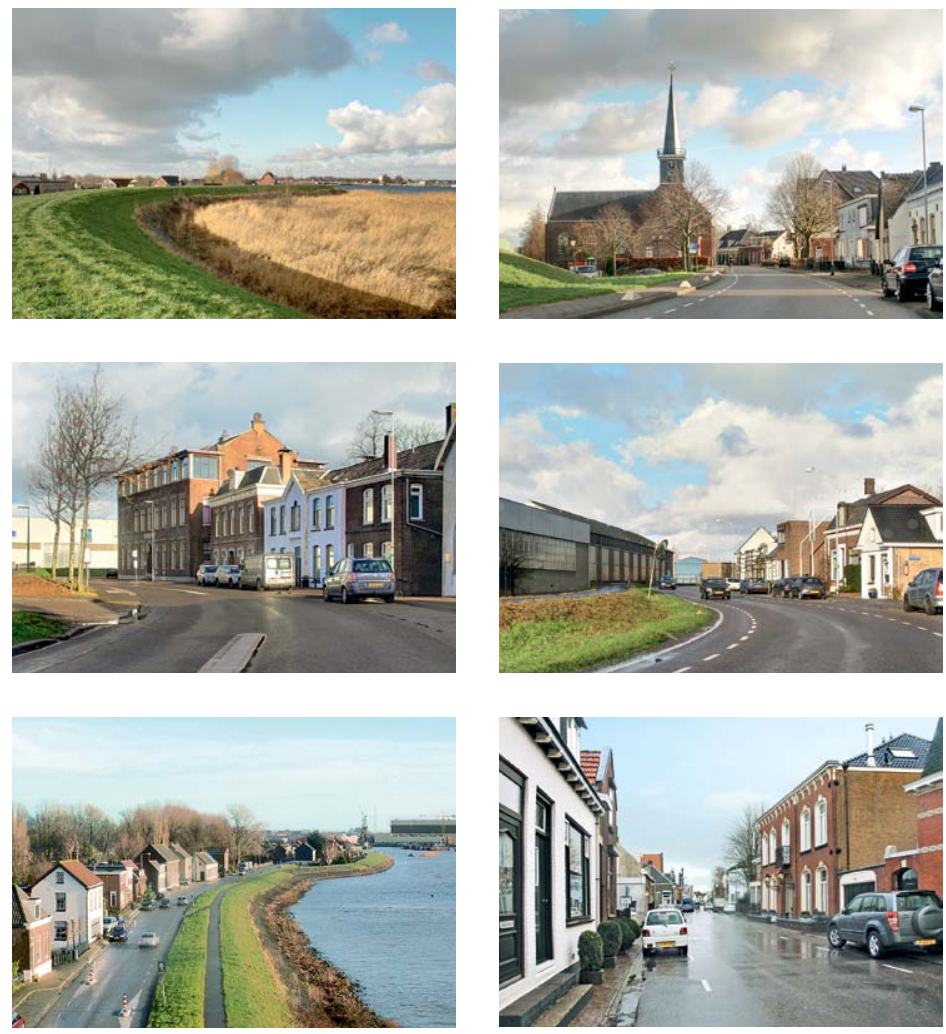

Applying the spatial assessment framework

The first step in the research was to apply the spatial assessment framework to the 'business-as-usual' flood-risk protection strategy in order to describe the effects of the strategy shown in figure 5 . The spatial assessment framework as described before was adapted to the specific situation of the Rijnmond-Drechtsteden area; criteria like future value, feasibility of gradual development, logic of the spatial arrangement, and seasonal attractiveness were added by the expert team, consisting of two urban designers, two landscape architects, and an ecologist.

The spatial assessment method is described in detail in an article by Anne Loes Nillesen in the Municipal Engineer (2013). Here, some exemplary assessments are briefly described. A selection of the sections assessed is shown in the left column of figure 8 . We see that according to the water levels predicted, the dyke in section $\mathrm{E}$ would have to be heightened by 48 centimetres. According to the civil engineering expert this requires either a quay wall or an elevation of the dyke along the waterside, both options are shown in more detail in figure 9 . As the expert panel concluded, the first option would be an inappropriate element in this area and interrupt the continuous space of the square to the river; the second option would cause the same interruption and change the historic character of the dyke as a result of the more gradual slope. Both options scored negative. However, the expert panel indicated that a dyke raising of 30 centimetres would be neutral if the raising is designed as a continuous but sloping public space.

The local impact on the scale of the section is already related to a larger scale perspective. This is demonstrated by the assessment of section B, shown in detail in figure 9 . The dyke reinforcement blocks the view of 


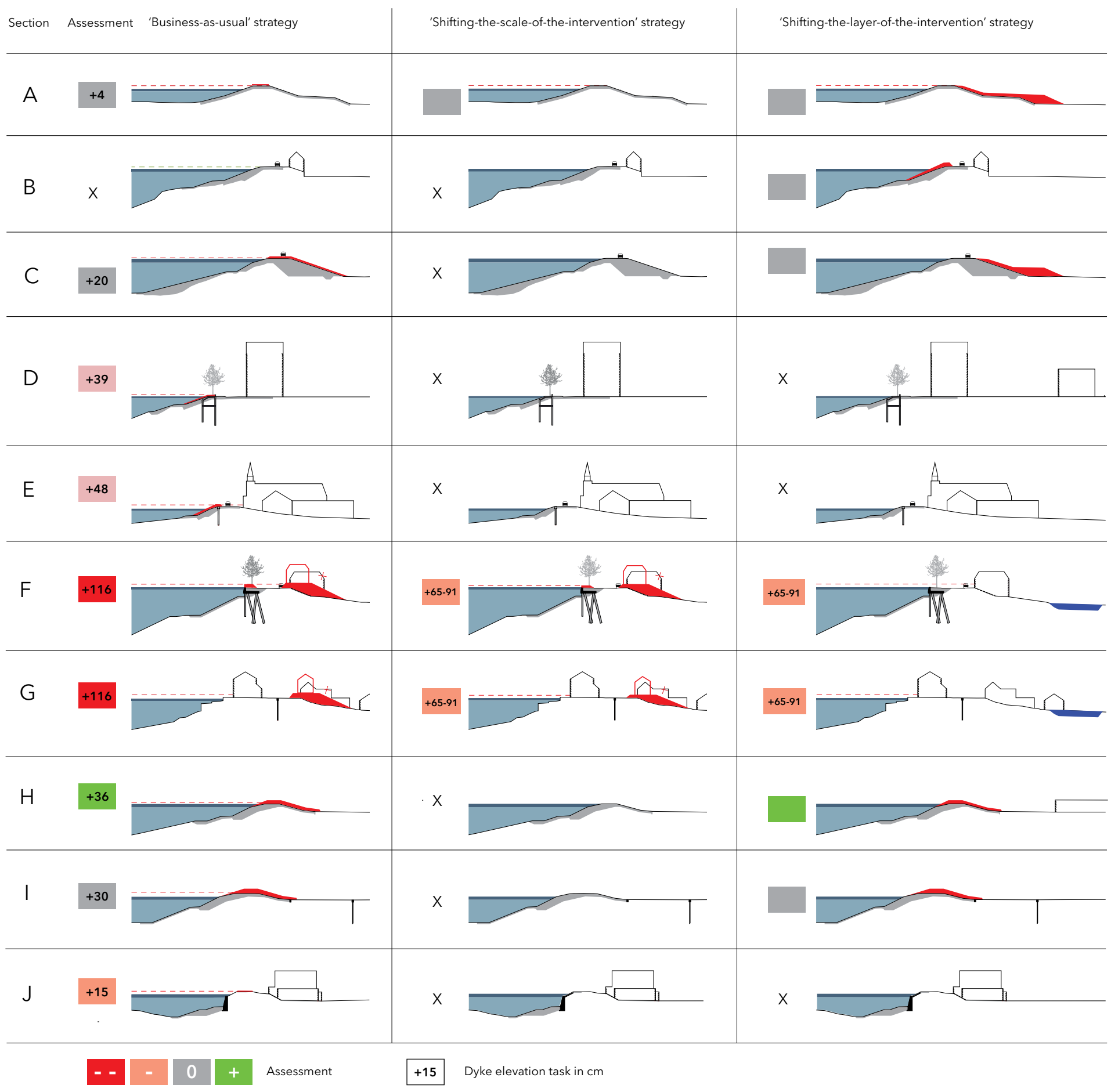

Figure 8 Example of sections used in the assessment of the impact of the different flood-risk strategies on the local-scale spatial quality. (Data on section: Water Board; data on normative water levels: vd Kraan 2012) 


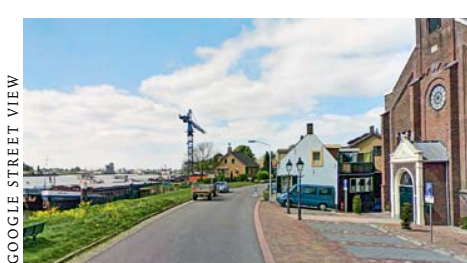

Section E: historic Merwede dyke

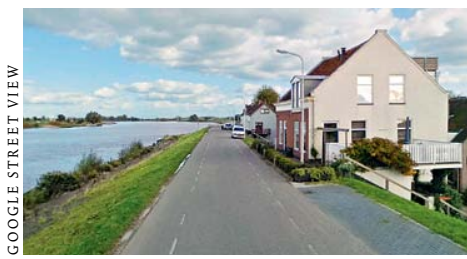

Section B: current situation, dyke along the Lek

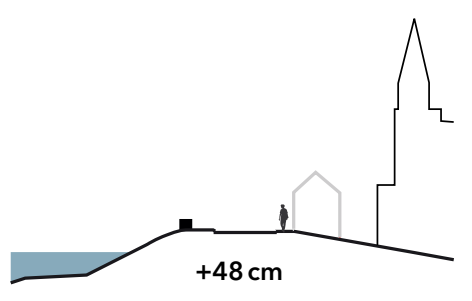

Intervention 1: quay wall

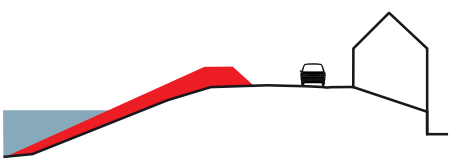

Dyke elevation on the local scale
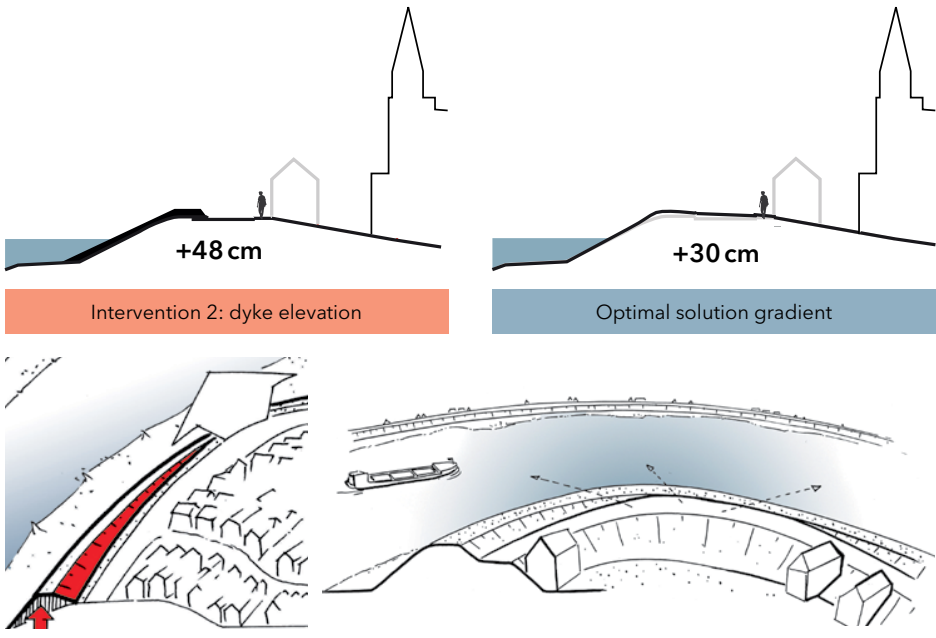

Interesting sequence in the wider context: view to the river in the bend

Figure 9 Detailed example of sections $\mathrm{E}$ (above) and B (below) used in the assessment of the impact of flood-risk strategies on the local-scale spatial quality

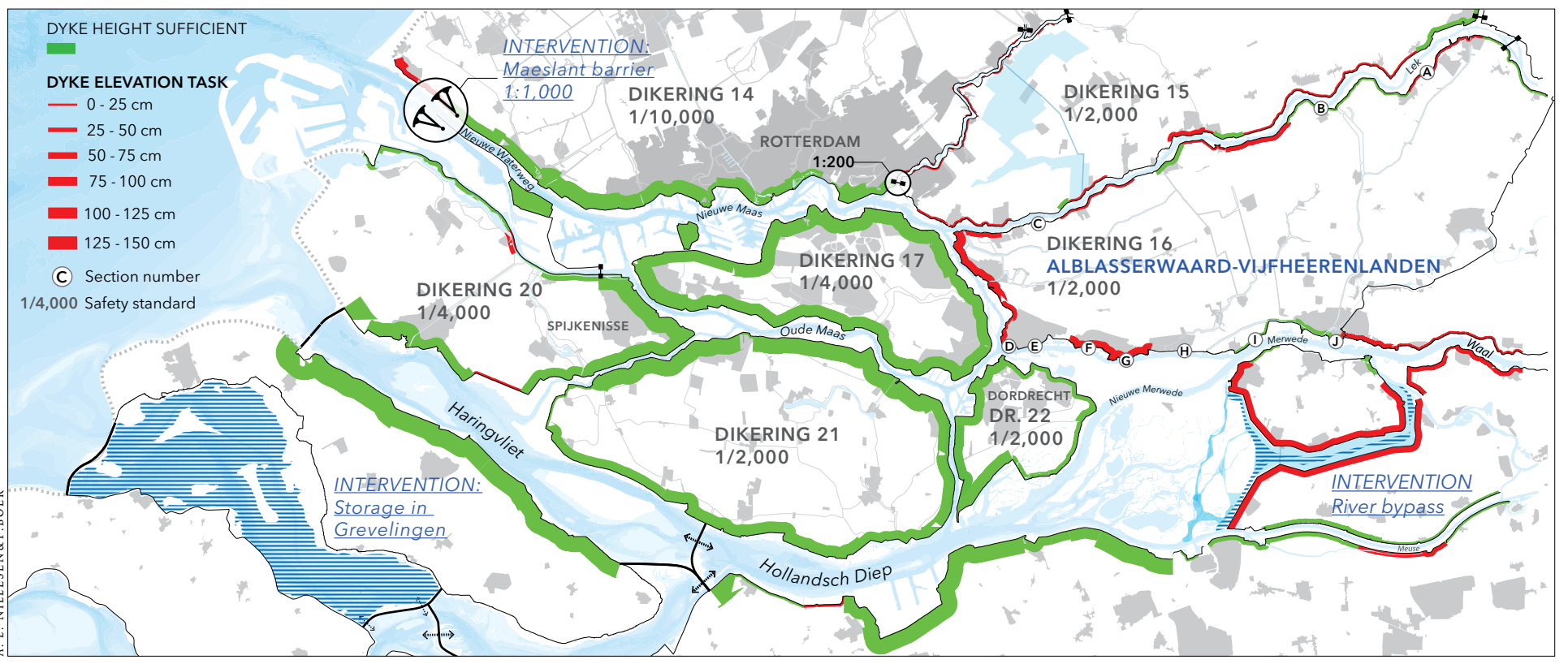

Figure 10 Indication of the regular dyke raisings planned until 2100, with the flood-risk protection strategy including land subsidence and climate change, an improved Maeslantkering, and a new green river and water storage at the Grevelingen Lake (Data: Deltares 2013) 
the river from the main road, a situation that in other sections has been assessed as negative. But in this case, on the larger scale the reinforcement creates an interesting sequence of blocking and allowing views. The same applies to the historic buildings in sections F and G. The demolition of incidental buildings does not harm the overall character, whereas completely restructuring the dyke would eliminate its existing, distinct character. For section $\mathrm{H}$, raising the dyke could create the opportunity for a landscape park and is assessed positive.

\section{Shifting the scale of flood-risk interventions}

In order to demonstrate the impact of a large-scale flood-risk intervention and its ability to shift the local flood prevention measures, the floodrisk strategies from the Delta programme are considered, including the improvement of the Maeslant storm surge barrier, additional water storage capacity in the Grevelingenmeer, and a bypass along the River Merwede. Figure 10 shows the effects on the normative water levels and thus on the local assignment to raise dykes for the combined flood-risk interventions. We see that some local assignments for the Alblasserwaard have shifted. The middle column of figure 8 shows the impact of the regional flood-risk interventions on the local-scale interventions in more detail. Compared to the 'business-as-usual' strategy in the left column, some of the negatively assessed flood-risk interventions (sections D, E, and J) disappeared or reduced (sections $F$ and $G$ ) from 116 centimetres to approximately 65 to 91 centimetres. This reduction changed the assessment to a less negative score, since the more modest dyke raising task extends the timeline of the necessary intervention. In this case a more gradual transformation of the existing characteristics of a ribbon consisting of different houses from different time periods could be achieved.
Shifting the flood-risk layer of interventions

The western part of the Alblasserwaard is positioned 3.5 meters lower than the eastern part. In figure 11 it is shown that the eastern dykes would take a relatively large share in the potential damage caused, since a dyke breach at the eastern part of the dyke ring would flood this ring in its entirety. In the first round of interventions, it is proposed to strengthen the eastern dyke sections. Calculations show that the reinforcement of those sections alone to a 1:100,000 standard would reduce the number of fatalities by 60 percent.

Possible consequences are further reduced by interventions from the second layer focussing on local areas that suffer a large share of the economic damage or the number of fatalities. In figure 11 and 12 it is shown how the damage in some areas that inundate quickly and deeply can be reduced by setting up life-saving flood shelters.

In figure 12 another example of the interchangeability between interventions in the layer of the probability and consequence reduction is shown. The calculated water levels consist to some extent of wave heights: according to a rule of thumb, expressed during the expert session, the wave height makes up approximately 50 centimetres of the normative water level. The damage caused by the overtopping of waves is considerably less then than the damage caused by a dyke break. In order to postpone problematic dyke reinforcements in sections $\mathrm{F}$ and $\mathrm{G}$, it could be decided to maintain the current dyke heights and collect the water that tops over in a water retention area behind the dyke. Such a retention area may coincide with current requests for extra rainwater storage. 


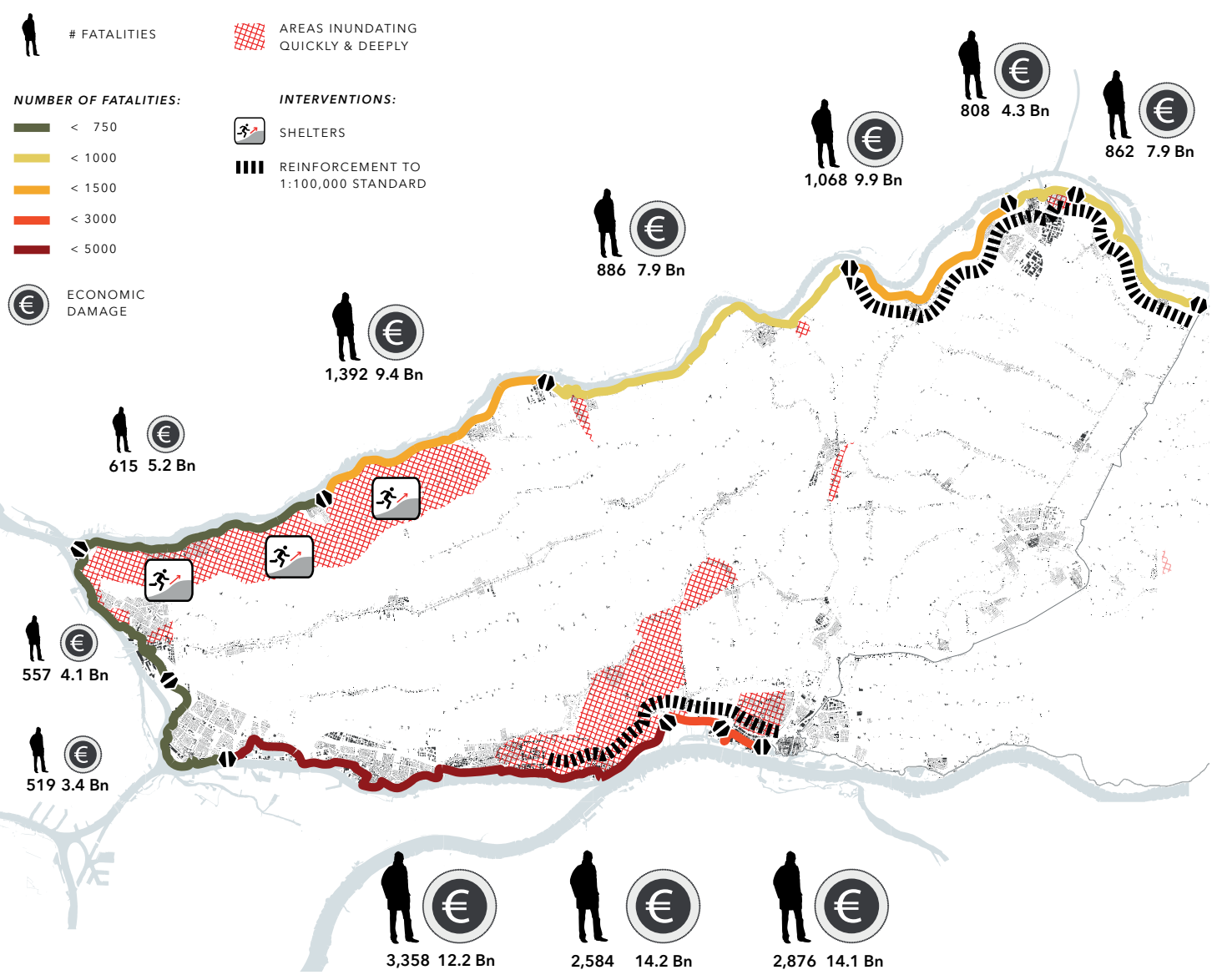

Figure 11 Schematic representation of the potential share of different dyke trajectories in the amount of economic damage and number of fatalities (Data: Deltares) and the proposed flood-risk interventions on different flood-risk layers.

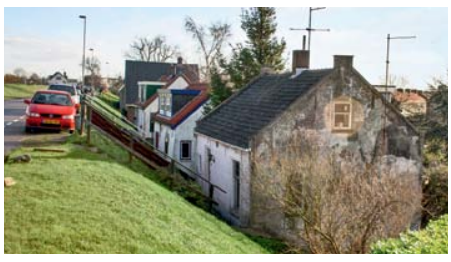

Dyke along the high-risk area along the Lek

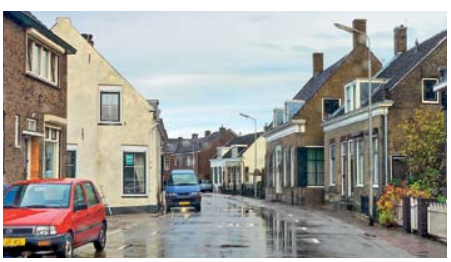

Section G: current situation historical dyke
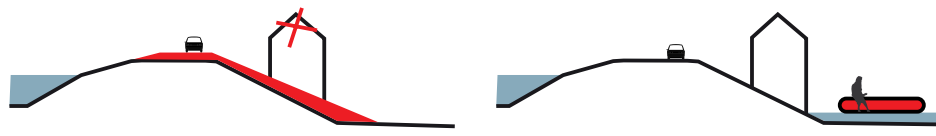

Protection: dyke elevation / house removal

Shelters to reduce consequence

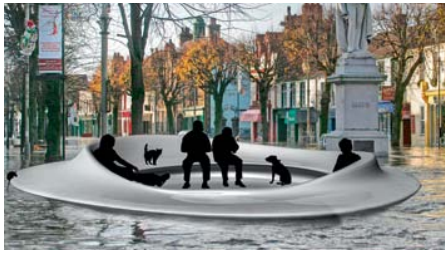

Floating shelters / street furniture

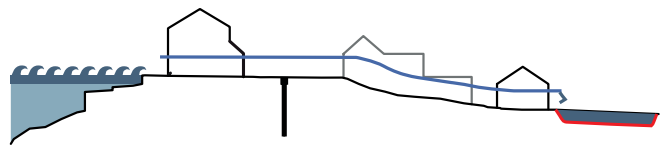

Reducing consequence: storing water overtopping the dyke

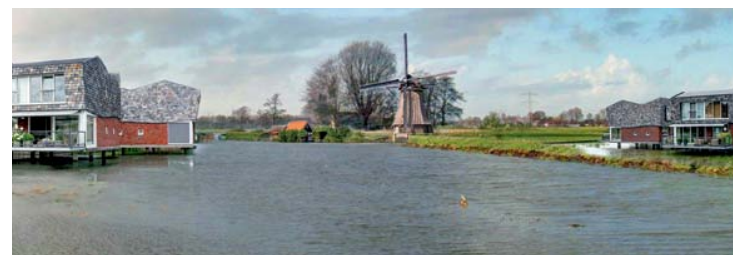

Impression of storm- and rainwater storage basin

Figure 12 Raising the dyke and constructing extra shelters as alternatives for risk reduction 
Conclusions and recommendations

The research-by-design methodology defined and evaluated in this study demonstrates how the aspects of scale and flood-risk intervention layer can be systematically employed to shift the location of a flood-risk intervention to a, from a spatial point of view, more suitable location. The concept of the scale of the intervention, when applied in the dyke ringdominated Rijnmond-Drechtsteden area, primarily facilitates shifting a flood-risk assignment along a dyke. The concept of the flood-risk intervention layer extends the possible locations for flood-risk interventions towards the inner dyke area.

The method includes:

- An inventory of the current and potential flood-risk protection strategies

- An inventory of the spatial characteristics, assignments, ambition, and potentials of the region

- A qualitative assessment of the existing situation and, if available, a reference flood-risk strategy

- Systematic research-by-design on how different flood-risk interventions on different scales can shift the local flood-risk assignment (and a qualitative evaluation of this shift)

- Systematic research-by-design on how interventions in different floodrisk intervention layers can shift the local flood-risk assignment (and a qualitative evaluation of this shift)
In order to apply the method in the manner of a spatial assessment framework for weighing different flood-risk strategies on the scale of the Delta, the method should include an assessment of:

- The effects on local-scale spatial quality for the entire area that is influenced by the flood-risk intervention

- The effects of interventions on a regional scale on spatial quality

The proposed methodology gives the designer the opportunity to actively participate in the debate concerning the location and scale of floodrisk interventions, resulting in a more integral design approach. The systematic approach and the strong connection to variables and data sets makes it easier to communicate the propositions from a spatial point of view to engineers working on the Delta Programme.

The method can be relevant for other urbanized delta areas. Obviously, the criteria for spatial quality will have to be adjusted to the local situation, in collaboration with an expert panel. The types of data used in this research are commonly used by engineering companies throughout the world. Although different companies use different models, the type of data used to support delta decisions are often similar.
References

Topos 64: 36-42.

Atelier Kustkwaliteit et al. (2013), Werkboek \#10 Atelier Kustkwaliteit 2013: Veiligheid en kwaliteit van de Nederlandse kust: op weg naar 2100 [report], www.atelierkustkwaliteit.nl/public/ uploads/pdf/Slotpublicatie Atelier Kustkwaliteit.pdf, accessed 1 July 2013.

Baca Architects et al. (2009), The LifE Project: Long-term initiatives for flood-risk environments (Bracknell: IHS BRE Press).

Bos, M., Lagendijk, O., and Beusekom, E. van (2004), Ruimtelijke Kwaliteit in de MER Ruimte voor de Rivier (Utrecht: Projectorganisatie Ruimte voor de Rivier).

Deltacommissie (2008), Working together with water [report]. www.deltacommissie.com/doc/deltareport-full.pdf, accessed 1 July 2013.

Gehl, J. et al. (2006), New City Life

(Copenhagen: The Danish Architectural Press).

Hooimeijer, P., Kroon, H., and Luttik, J. (2001),

Kwaliteit in meervoud (Waddinxveen: A-twee).

Expertise Netwerk Waterveiligheid (2012), Meerlaagsveiligheid nuchter bekeken: November 2012 [report], www.enwinfo.nl/ upload/Meerlaagsveiligheid-nuchter-bekeken-20121130.pdf, accessed 1 April 2013.

Jong, T.M. de and Voordt, D.J.M. van der (eds.) (2005), Ways to study and research: urban, architectural and technical design (Delft: DUP Science).

Jonkman, B., Kok, M., and Vrijling, H. (2008), 'Flood-risk Assessment in the Netherlands', Risk Analysis 28/5: 1357-1373.

Klijn, F. et al. (2013), 'Design quality of Room-for-the-River measures in the Netherlands: role and assessment of the Quality Team (Q-team)', International Journal of River Basin Management DOI: 10.1080/15715124.2013.811418.
Meyer, H. (2009), 'The Dutch Delta: Looking for a new fusion of urbanism and hydraulic engineering', in Feyen, J., Shannon, K., and Neville, M. (eds.) (2009), Water E Urban Development Paradigms (Leiden: Taylor and Francis).

Meyer, H., Morris, D., and Waggonner, D. (eds.) (2009), Dutch Dialogues: New Orleans - Netherlands; Common Challenges in Urbanized Deltas (Amsterdam: SUN).

Nillesen, A. and Singelenberg, J. (2011), Amphibious Housing in the Netherlands (Rotterdam: NAi Publishers).

Nillesen, A. (2013), 'Water-safety strategies and local-scale spatial quality', Municipal Engineer 166: 16-23.

Prominski, M. et al. (2012), River.Space.Design (Basel: Birkhäuser).

Provincie Zuid-Holland, Provinciale structuurvisie [online text], www.zuid-holland.nl/visieopzuidholland, accessed 1 July 2013.

Steenbergen, C.M. et al. (2009), De Polderatlas van Nederland (Bussum: THOTH).

Stokman, A. et al. (2008), Wasseratlas (Berlin: Jovis Verlag).

Veelen, P. van et al. (2010), Veilige en goed ingepaste waterkeringen in Rotterdam (Rotterdam: Knowledge for Climate).

UN-Habitat (2006), State of the World's Cities 2006/07: The Millennium Development Goals and Urban Sustainability: 30 Years of Shaping the Habitat Agenda (Nairobi: UN-HABITAT).

Waterschap Hollandse Delta, Dijkversterkingsprogramma [online text], www.wshd.nl/dijkversterkingsprogramma/ algemene-onderdelen/over-het-programma, accessed 2 April 2013.
Biographical note

Anne Loes Nillesen is a researcher at the Delft University of Technology where she is the coordinator and a teacher of the Delta Interventions graduation studio and a member of the Delta Urbanism research group. She is also the founder and owner of the urbanism and landscape architecture office D.EFAC.TO where she is involved in multiple water-related urban and landscape design projects. In 2011 Nillesen published the book Amphibious Housing in the Netherlands.

Contact

Anne Loes Nillesen

Faculty of Architecture

Department of Urbanism,

Delft University of Technology

Julianalaan 134, 2618BL

Delft, The Netherlands

a.l.nillesen@tudelft.nl

D.EFAC.TO Urban Design

Henegouwerlaan 37A, 3021CR

Rotterdam, The Netherlands

Phone: +31-(0)644818169 